\title{
The Link Between Topic Work and Intrinsic Motivation
}

\author{
Shqipe Haxhihyseni \\ Universiteti "Aleksandër Moisiu" Durrës \\ shqipeshyti@yahoo.com
}

\section{Doi:10.5901/ajis.2013.v2n8p311}

\begin{abstract}
This study explores the relationship between topic work, as a teaching and learning method based on the philosophy of open classrooms and pupil's motivation. Topic work, as a methodology emerged in our school after 1990's, to support democratization in the relationship between teacher and pupils. Topic work had a stretch in Elbasan's schools for more than 8 years, while this methodology has a long story and has been adopted across European and American schools. In these countries, the method continues to grow in its popularity. In the beginning, this paper will describe the principles of topic work based on literature about this theme, and the role of motivation in the attitude of children towards school. The motivation, likewise is analyzed based on recent findings in the educational psychology field. Comparing the principles of topic work, with elements of motivation especially of intrinsic motivation, it will be concluded that topic work as methodology includes a lot of elements of intrinsic motivation. With the changing of curriculum demands, teachers can rely on this methodology to motivate pupils, to be closer to their needs and closer to recent developments in education policy.
\end{abstract}

Keywords: topic work, motivation, intrinsic motivation, needs of pupils, teaching and learning methodology

\section{Introduction}

The diversity of students, the characteristics of their experiences in school, is present and visible. These characteristics and personal experiences contribute to their motivation. However, teachers as well can make a difference, for better or worse, to motivate students to learn. Some students are concerned about grades, others should necessarily participate in an optional subject. Still others want to learn and explore ideas. In fact, many students are probably motivated to learn and succeed by a combination of elements of intrinsic and extrinsic motivation. The key for us as teachers is to understand what we can do to build students' motivation to learn in our class, and cultivate internal motivation that will lead to learning in the future, because our ideal goal as teacher is to help students develop internal motivation that will allow them to be lifelong learners.

Intrinsic motivated students want to learn, because they are curious, they want to improve, they seek knowledge, learning gives them pleasure, and for those who are not internally motivated, the teacher is the one who does so, by going out of the routine, and bringing learning closer to learners. Topic work is an opportunity for this.

This study will analyze the elements of intrinsic motivation, and features of topic work, to conclude the strong link that exists between the topic work, as an element of open classes and intrinsic motivation of students.

Scrutiny of motivation, especially internal motivation, as treatises on contemporary literature, and its importance in the learning process will be the first part of the analysis to be done. This will be followed by analysis of topic work as a methodology on its specific characteristics and little known across the country, it will be treated not only on how it is organized, but with the elements that characterize this methodology. In this way, the link between topic work and motivation will be more obvious, and certainly more convincing to all those teachers who aim to increase students' motivation, as topic work method enables internal motivation levels are higher than in traditional learning .

Because students have different interests and different ways of viewing and perceiving the world, the optimism of children to their interests determines which education is best for them, and in this way a classroom can be created with an environment that will encourage them to choose their activities. The ways of organizing topic work creates priority for the establishment of the class environment that promotes cooperation and emphasizes affective abilities of each child.

This methodology assumes that the teacher's role is not to control students, but to enable them to make choices they like and to pursue them . This does not mean that the teacher should expect the same from all students. A teacher who applies this methodology should be able to cultivate unexpected expectations, the student can show his skills, regardless of what the teacher has chosen for him. Parents who believe that children should always learn individually, 
should not forget that the student learns and experiences from the group.

\section{Motivation}

Psychology considers motivation as a term that includes a wide range of variables, resulting in a multitude of definitions and theories. Yet many researchers(Dörnyei, Z. 2001: p .8). are of the opinion that motivation has to do with running and magnitude of human behavior, in other words, is associated with the selection of an action, and persistence in it, and the efforts made in it

Theories of motivation occupy an important place in psychology, because motivation plays an important role in human life, the way we not only learn, but learn and move forward in life. Usually, the motivation is defined as an inner state that enlivened, promotes and support the behavior. Psychology of Education believes that motivation is an important concept in theories of learning.

Intrinsic motivation is defined as doing an activity for personal pleasure. When you are internally motivated, you move to act for fun, or for challenging the activity. For example, if given the opportunity to choose a topic for a research, the child is motivated to do the research and to spend more time on the project. The result is that the student gains a better grasp of the content and is more satisfied with the work done. Being internally motivated, means that a person has an inner wheel to perform a task and completes it to his satisfaction. Some factors affecting the internal motivation are: self-determination, / autonomy, curiosity for the subject / activity, competence in skills and habits, one's pleasure to make a connection with activity and which the individual values for the same things with someone is very close (Baard. P.Paul, 2002: p.259). Some illustrations of these factors are:

Self determination / autonomy: A student chooses to read over the material required to fulfill his personal pleasure reading. This shows self-determination in the student because he is doing something for his personal motivating reasons.

Competence in skills habits: If a teacher allows the student to choose what he wants for a research or design student who has talent in literature will write a report search, because he has the power of writing.

Family Background: A student who has a relative doctor will be more interested in science (anatomy, biology), because he considers it to be appreciated by his parents.

Intrinsic motivation stimulated by tasks, difficulty, personal interests and help control personal choice. Curiosity, flexibility, critical thinking and creativity are indicators of intrinsic motivation for learning, which have a large function with basic needs and match the exercise of personal control.

Intrinsic motivation is seen as a born necessity, which begins in childhood years, as the need for power and determination, it is encouraging for exploring, learning and to challenge ourselves. Ryan and Deci ( Deci and Ryan, 2010) defended the idea that intrinsic motivation underlies human behavior without the need for external rewards and has three basics needed to manage behavior, competence, autonomy and independence. According to this theory, these three basic needs are necessary to enable growth, social development and well-being. The relationship between intrinsic motivation and extrinsic motivation not characteristic and the impact of this relationship in human growth, development, needs are developed in the theory presented by Decin and Ryan , The theory of Self-determination (Decin and Ryan, 2010).

Although intrinsic motivation has its origins in childhood, Deci and Ryan (Decin, and Ryan, 2010) describe intrinsic motivation as the 'eternal source of creativity'. This highlights the importance of intrinsic motivation and close relationships it has with creativity, and clearly this should not be overlooked, because as a result of perceived competence and autonomy will be essential to ensure that childhood games take place in the adult creativity.

Intrinsic motivation includes involvement in a fun activity and fulfilling that activity. Students complete their tasks because they enjoy and find that learning new things is interesting and pleasing, can be said to be internally motivated. Vallerand and his colleagues (Vallerand, J.Robert, Catherine F, Ratelle, 2002: p.42) suggest a taxonomy of IM ( intrinsic motivation). First, acquaintances includes engaging in activities for enjoyment that comes from learning, exploring and understanding new things. Secondly, doing things refers to engaging in fun activities stems from the attempt to surpass themselves, to create, to accomplish something. Third, to test incentives when you engage in an activity because feelings associated with it are stimulated.

According postulate 5 of Valerand., motivation leads to important consequences:

1. Positive consequences of reduced IM in EM, and IM specifically leads to positive consequences, followed by integration and identification. External regulation may be associated with adverse consequences and amotivation is one of these.

2. Perceived competence and autonomy (psychological factors), self determining situational motivation and 
concentration of targets for sustainability in the future (motivational consequences) are measured variables and has emerged that the success/failure affect perceptions of competence and autonomy, which influence situational self-determined motivation. At the end we can say that motivation predicts concentration and behavioral goals in the future

\section{Methods to promote intrinsic motivation.}

Intrinsic motivation is important for people to develop lifelong learning, but it is difficult to see in many classrooms. For example, Deci and Richard (Ryan. M.Richard and Deci. L.Edward, 2000, p.55).discovered that money as a reward has harmful effects on motivation. Students become less motivated when rewarded with money in return. On the other hand, when students are given a prize as a reward they are more motivated. In addition they found that when a person perceives a reward that is more than they deserve, that person puts more effort to an activity. So, to promote intrinsic motivation, is necessary :

A. To create a climate of autonomy in class. Many researchers believe that the development of an autonomous class climate is a very good method to promote internal motivation. Paynter (Paynter, JL, 2004) states that "when students feel in control of their environment they are internally motivated to work, and may have positive self-esteem and feelings. She studied children performing arts activity. A group of children were left to choose some materials to work, and the other group was assigned materials to be used. She found that children who chose the materials were judged as more creative and they spent more time on the activity. According to her, this fact has important implications. With the increasing demand and rising child in school, while they need to be more motivated. Students were given more choices in their learning were more internally motivated than those who were assigned to the elections.

B. Giving a child choices. Koestner (Koestner, R., 2008, p. 60-67). suggests that there are many ways to give children choices in the classroom. With respect to academic learning, children can make choices to those that they learn quickly, choosing books to read, learn how to choose the setting group with whom to work, or where they will work in the classroom. The students can make their own choices in what they learn better than helping to determine the criteria on which their duty will be assessed. In the end, Koestner emphasizes the involvement of children in discussions about social and behavioral issues in the classroom, as the rules and procedures to be followed. Children can give solutions on these issues which should better be taken seriously. So, it must be said that children should be given the opportunity to make decisions about their learning, materials to be used and the way to work, all in order to reach the school's goals.

\section{Topic Work}

Topic work generally is open and not closed in terms of teaching-learning relationship. Goals of topic work are usually unknown to the student so that the student is free to have his reasons for doing it. If this is done, it helps children to decide what they can get out of it, and make it possible for the student to identify his targets. Unlike behavioral objectives that are widely used in schools, this method does not narrow the scope for the children learning .

The Topic for each topic work is based on the interests of the child, because children are more likely to be interested in topic work which have themes that are closely related to their interests.

The fact is that these methodology is successful in the world and has given satisfactory results in the education of the young generation, remains to us this chance to give younger generations. Thus, in recent years more emphasis has been put on how students learn and the quality of their learning. Thus some subjects are taught through Labor topics (in America, Norway, Denmark, etc.). While in Scotland is the most widespread methods Story Line, which is basically working with principe of topic work. These methodologies consist in the integration of subjects, so history, geography, science, education can be studied as part of a wider body of knowledge. But it can develop and work on a single subject or theme set by which the integration subject.

Preparing for the 21st century and change of the curriculum have made it possible to enter the interdisciplinary curriculum to include education, protecting an interdisciplinary vision for our schools. Today, interdisciplinary learning has become more accepted in planning the curriculum, creating opportunities for teachers to plan interdisciplinary units with confidence, courage and understanding.

Teachers are those who give inspiration and guidance to children, create opportunities for learning skills in a natural way, develop a large range of possibilities for different interests and development and individualize grade level for 
each student progress.

Traditionally, a teacher can begin work on the topic by reading a chapter and make specific inquiries about it that are related to the content. In an open situation he can place children in a circle and discuss about their favorite game.

According to the opinions of teachers, the most successful approaches in a number of strategies to increase students' interest in learning, include learning in collaboration, allowing alternative solutions and encouraging creativity. Students share ideas together and then organize their thoughts with each other. Then they begin to write individually.

topic work as an approach challenges the traditional role of teachers as providers of information and requires the teacher to take a step forward in the role of facilitators, and planning of the learning topic. topic work is built between teachers and students, and students are given autonomy in their learning. Moreover, the teacher is encouraged to learn from and together with the students in their classroom, assessment of knowledge that students bring to the classroom. topic work is not based on external compensation, no tests, certificate or other form of assessment. Topic work process is guided by the students and the way in which problems are addressed and resolved is determined by the pupils. In this way, many of the common extrinsic motivators, such as test scores, exam pressures and reward systems, widely encountered in the context of today's educational approach fade from topic work. In the method of topic work students make their choices in the learning topic and pursue their interests in topic work For these reasons, it is logical to conclude that the topic work as a method may be closer to intrinsic motivation.

\section{Link between TOPIC WORK and intrinsic motivation}

As we stated above, topic work is a cross-curricular method. Topics may focused mainly on reading and counting, while in a number of areas learning will be applied as well, other subjects will be involved and when necessary, learning to make intersections with other disciplines. Topic work fosters a creative approach to teaching and learning, this method brings the combination of learning and experience brings freedom for both parties: teachers and students. Techniques for problem solving, creative thinking, decision-making and working with others are all necessary skills for students to develop when treatment is undertaken by topic work method. This method is characterized by seeking endlessly, and in topic work creativity is a primary importance. The teacher's role is to facilitate learning and working together with students, the teacher is therefore dependent on contributions from students with ideas and solutions to topic work problems.

The three dimensions required in this model by Amabile(Amabile, TM, 1997. p.39-40), are the key skills, so, creative thinking, work skills, and intrinsic motivation. Describing the background of the key skills that we possess the knowledge, skills and creative abilities will describe the work to take risks and experiment, intrinsic motivation (as discussed) is the motivation to complete the task for the sake of the task itself. When three factors come together and overlap, this process is described as "creative junction." Amabile asserts that only when all three factors are true potential can then creativity flourish.

Deci and Ryan (Decin, EL, and Ryan, RM, 1985) found a close relationship between human creativity and perceptions about control, perceived choice and interest levels. When all these factors are placed in harmony with each other, they defend the idea that the levels of creativity and intrinsic motivation will increase.

Accessing the topic work is essentially a creative approach to the curriculum and as such it should have the key skills defining, job skills and a learning environment in which promote intrinsic motivation. topic work method takes as a starting point, based on students' knowledge and understanding about the subject that they bring to the classroom, and these are the main determinant skills. topic work method provides us with a problem in the classroom so that should be resolved and so are the job skills necessary to take risks and experiment to find solutions. Education determines that the topic work method is driven by extrinsic motivation, rather than the students having ownership of their learning and becoming motivated (internally) in the context of topic work itself and the problems they have to solve. In Amabile's research (Amabile, TM, 1998, p.77-78).about creativity she found a link between creativity and the increase of intrinsic motivation. She describes them as creative individuals as "expertise", with good skills and creative thinking, and high levels of intrinsic motivation.

Through Amabile's research for creativity and impact of the work environment, have emerged these main categories:

1. challenges

2. freedom,

3. resources,

4. work-group, 
5. encouragement from the supervisor,

6. organizational support

Amabile defends the idea that these categories are fundamental to the growth of internal motivation and ultimately to support creativity in the work environment.

Within the characteristics of the working group, the class is organized to work in a variety of situations in pairs or groups and students to create groups that support family values and working with others. In a topic work the teacher facilitates learning, but support is given oversight by encouraging active participation, inviting experts in classroom learning and celebrating the end of the topic. The learning environment is essential to the success of a topic work, because the climate of the class should support the idea of the imagined world that has created classes together and support should be given to how classes cooperate in their learning.

Students in a topic work are challenged to solve problems and find solutions, and they have the freedom to make their own choices and decisions throughout the process. Open source used by students to design and create models and situations, and as previously set the topic work method will now be evaluated closely related to the main features of motivation. From the Leper Hodell (Lepper, MR and Hodell, M., 1989, p.73-105) it is thought that there are four key strands of intrinsic motivation, challenge, curiosity, control and fantasy.

An explanation of these origins is shown in the figure below:

\begin{tabular}{ll} 
Source & Implications \\
\hline Challenges & $\begin{array}{l}\text { The presentation students with tasks of an average difficulty they feel effective in } \\
\text { meeting its }\end{array}$ \\
\hline Curiosity & $\begin{array}{l}\text { Presentation of students with information that will surprise motivate them to close } \\
\text { the gap between their knowledge }\end{array}$ \\
\hline Control & $\begin{array}{l}\text { students were given a sense of control and choice in learning the results of their } \\
\text { learning }\end{array}$ \\
\hline The fantasy & involves students in fantasy and imagination through simulations and games
\end{tabular}

Tab.1. Four key of intrinsic motivation

\subsection{Challenge}

Ryan and Deci (Deci, EL and Ryan, RM, 2000:54-67) suggest that the key to motivating students is basically a challenge. Before starting a new topic work, classroom teacher finds out what knowledge students bring to the topic and what gaps there are in the understanding that they can show. With the progress of the topic work, collectively challenged, the class is to help solve a difficult situation or problem.

The teacher facilitates the learning of new skills and helps develop existing skills, working together with the students. Students are challenged on an individual level, giving part of the task to work on. Through this, they are able to not only develop their skills, but also to improve them. At the end of the unit there is no test.

Learning is the ability to direct, and students are motivated to reach a satisfactory solution to a common problem. In this way learning is differentiated and students are challenged on an individual level, suitable to their needs. As a group, students are challenged to determine the outcome of topic work, seeking solutions to problems and taking risks and experimenting with new ideas, develop their job skills (Amabile, 1997.p.39-58).

\subsection{Curiosity}

Topic work premise begins with the knowledge that the students bring to the topic, students are not seen as empty vessels. The teacher determines what knowledge and skills students have and identifies areas that are less popular. With the development of the topic work, students are presented with issues that require a solution. Through this method, the student's curiosity grows and students are eager to use their existing knowledge which they have acquired in topic work so far (and fill any gaps) in order to come up with a common solution to the problem. Curiosity, as one of the four strands of intrinsic motivation is also associated with other motivational theories that surround the topic of interest (Hidi, Renninger, and Krapp, 2004).

In relation with an educational context, advocates of the theory of interest, support the idea that students are most effective when they keep their personal interest in their learning. Personal interest can be a useful and positive emotion in a classroom context, since the interest can promote applied and detailed learning. Interest method is used in the topic 
work enough to stimulate students' interest in the work, using unexpected events, or the arrival of a letter as a context for learning.

\subsection{Control}

Giving a sense of control over learning is seen as essential to promote intrinsic motivation. (Ryan, RM and Decin, EL, 2000 Vol 55:1, p.68-78) Facilitating of the control can be done through allowing students freedom of choice or including students in decision making.

Topic work learning becomes a shared experience between teachers and students. It's as an approach that involves the inclusion of students in the learning process and leaves behind the traditional role of the teacher as the source for all the information, but rather brings with it the teacher as a facilitator in the learning process. Teachers course that controls and directs the structure of the topic and identified the desired learning to be undertaken within its students, but topic work developed as a result of contributions and students' responses.

While the topic work as an approach is based on the methodology of child-centered, progressive traditions, unlike some progressive approaches, it makes the same mistake with emphasis on the child, at the expense of new learning. Clearly, it is essential for topic work students to have a voice, their learning builds on what they already know and thus, the result of topic work is led by students and choices they make. During topic work students decipher what they need to know in order to complete the topic work and in doing so they create their own questions. However, it is the teacher who provides structure to find this information or writes biography, providing formats so that students are not only to fulfill their duties. This learning model promotes high levels of student control and therefore, intrinsic motivation should be high. Within this structure, students have the opportunity to enhance their determinative skills (knowledge that they bring) and their ability to work.

\subsection{Fantasy}

A further element of intrinsic motivation is fantasy. Lepper and Hodell (Lepper, MR and Hodell, M., 1989) believe that intrinsic motivation can be increased through the use of incentives and encouraging situations. Topic work also presents real life, giving students a context that is familiar, but allowing them to create an imaginary world within a real context. It's as method is built around a chosen theme, and the students construct their own learning by giving us the expected results. Imagination which is somewhat lost in our schools, is essential to the learning process and is important in all disciplines, not just subjects of art as some might assume. It must be said that traditional teaching leaves little room to imagination, as the teacher feels safer with standard answers from students, within the framework that the teacher, or the textbook predetermine. In the topic work method, students present their contexts in topic work class, they imagine themselves as characters and begin to recreate and make sense of the world they have created. Within this fantasy world, students and teachers can explore difficult themes, complex and often contradictory for a safe and secure classroom environment. It is clear from this statement that the topic work as a method is more closely aligned to the theory of intrinsic motivation.

Self-determination of goals, persistence on tasks, can be considered self motivation ingredients. Within classes where topic work is developed, there are a series of appropriate activities, and freedom of choice and opportunity for these activities, which can be developed in a natural situation, in which the teacher can observe. Below is given a summary of the topic work connection with internal motivation, based on the above analysis.

\begin{tabular}{ll} 
Intrinsic motivation & Topic Work \\
\hline Self-determination & Autonomy of decision-making goals for learning \\
\hline Persistence in problem solving task & Problem solving \\
\hline Self-evaluation & Is not based on external appraisal \\
\hline Competence (percevied choise) & Students make their choices \\
\hline Curiosity for learning / Satisfaction & Creativity
\end{tabular}

Tab.2. Connection betwen Intrinsic motivation and topic work 


\section{Conclusion}

It's time for our school to be more open, more democratic and for changes to take place in it. The need for change noted in SKPA 2005-2015, which states: "It is now a need to develop a curriculum requirement oriented and focused on knowledge and skills sufficient for active citizens of a democratic society based on market economy. Implementation of this requirement dictates the method over the existing "core curricula subjects" in "curriculum based on learning outcomes", according to which alternatives are open to new subjects and / or integration of subjects. (MASH, 2007). According to these goals, the school will:

- Improve cooperation between students and their creativity and independence in performing work

- increase positive attitudes toward school students

- raise motivation and satisfaction from learning

- increase school results and also those affective of students

All these lead to the democratization of relations in the classroom, enabling the realization of many goals that our schools today has in front, preparing its citizens for the future by educating the students respect and tolerance of lifelong learning.

All these can be achieved by following these steps:

- Thinking about the curriculum as a unit results from different subjects and related to each other, then go outside templates solid schemes.

- To build your class curriculum taking into account the background of every day experience of the child. The introduction of specific objectives that can help.

- To examine critically the curriculum guide. If you need to teach a specific unit, it must be found within the framework more flexible ways to seek and give children the opportunity to be directly involved in their learning.

- Children should be thinking about how things differ from the importance of simple possession of information and encourage the learning process.

- Planning should be done with the children and give them an acceptable solution can be accomplished in the classroom.

- More importance should be given to use of source material than to those in the textbook study.

- It should always be spoken with children to help them understand that teachers care about them as individuals.

- Must spend more time watching students carefully in order to identify ways in which they learn.

- A good teacher must know the child's interests, to support these interests, to develop a suitable activity and valuable in a large range.

The key role of teachers, as facilitators of learning, is to increase the opportunities that every child has, to be fully engaged in the activities of the day as much as possible, to encourage active exploration of the world of the child by the teacher itself, making it more intristically motivated. In this way it will be possible for the students to learn throughout life, and as topic work is a good method for this.

\section{References}

Amabile, T.M (1997) Motivating creativity in organizations: on doing what you love and loving what you do. California Management Review, 40, pp.39-58.

Amabile,T.M, (1998), How to Kill Cretivity, Harvard Business Review, September-October 1998, p.77-78.

Amabile,T.M,(1997), Motivating creativityin organozations: on doing what loving what you do. California Managment Review, 40, p.3940.

Baard. P.Paul,, 2002)Intrinsic Need Satifaction in Organizations: A motivational Basis of Succes In For-profit and Non- Profit Settings, Handbook of Self-Determination Research, The University of Rochester Press, USA, p.259.

Barth. S.Roland, (1973) Open Education and the American School, Agathon Press, Inc, New York, f.41.

Deci, E.L and Ryan, R.M (2000:) Intrinsic and extrinsic motivations: Classic definitions and new directions. Contemporary Educational Psychology 25, p.54-67.

Deci, E.I, and Ryan,R.M, (2010) Self-Determination Theory: Questionaires. Htttp://psych.rochester.edu/SDT/Questionaires.Php

Deci,E.L, dhe Ryan,R.M,(1985) Intrisic Motivation and Self-Determination in Human Behaviour.New York: Plenum Press

Dörnyei, Z. (2001:). Teaching and researching motivation. Harlow: Longman. p.8.

Hidi, S; Renninger, K.A and Krapp, A (2004) Interest, a Motivational Variable that combines affective and cognitive functioning. In Dai, D.Y and Sternberg, R.J (eds) (2004) Motivation, Emotion and Cognition. New Jersey: Taylor and Francis

Koestner, R. (January 01, 2008,). Reaching one's personal goals: A motivational perspective focused on autonomy. Canadian 
Psychology/Psychologie Canadienne, 49,1, p 60-67.

Lepper, M.R and Hodell, M (1989) Intrinsic motivation in the classroom. In Ames, C and Ames, R (eds) Research on motivation in education San Diego, CA: Academic Press, vol 3 pp73-105)

Paynter, J. L. (2004). The motivational profiles of teachers: Teachers' preferences for extrinsic, intrinsic, and moral motivators. Thesis (Doctor of Ed.) The Johns Hopkins University, 2004

Ryan. M.Richard dhe Deci. L.Edward, (2000) Intrisic and extrinsic Motivations: Classic Definitions and New Directions, Contemporary Educational Phsycologgy, 25,F.55

Ryan, R.M and Deci, E.L (2000 Self-Determination Theory and the Facilitation of Intrinsic Motivation, Social Development and WellBeing. Amercian Pscychologist, Vol 55:1, p.68-78.

Ryan. M.Richard dhe Deci. L.Edward, (2000) Intrisic and extrinsic Motivations: Classic Definitions and New Directions,Contemporary Educational Phsychology, 25, p.55,

Vallerand, J.Robert, Catherine F, Ratelle 2002, Intrisic and Extrinsic Motivation: A hierarchical Model, Handbook of Self-Determination Research, The University of Rochester Press, USA, p.42, 48-49, 52.

Strategjia Kombëtare e Arsimit Parauniversitar 2005-2015,Tiranë, Nëntor '2007 http://.mash.gov.al 